\title{
A New Day for Academic Psychiatry
}

\author{
Richard Balon • Eugene V. Beresin • John H. Coverdale • \\ Michelle Goldsmith • Alan K. Louie • Glendon R. Tait • \\ Laura Weiss Roberts
}

Received: 12 November 2013 / Accepted: 24 November 2013/Published online: 16 January 2014

(C) Academic Psychiatry 2014

Keywords Academic journal $\cdot$ Writing $\cdot$ Editing $\cdot$

Professional organizations $\cdot$ Impact factor

Progress is impossible without change, and those who cannot change their minds cannot change anything.

\section{George Bernard Shaw}

Academic Psychiatry was born to serve the teachers, learners, and leaders of psychiatry. As academic medicine and the mental health professions have evolved, the journal has undergone a progressive transformation to fulfill its fundamental purpose of service to our field. The milestones on this path, occurring over nearly four decades, are many, including a name change; inclusion in the National Library of Medicine database; ongoing expansion of our authors, readers, and editors; addition of new sponsoring organizations; the creation of special theme issues; more frequent and online publication; and increasing visibility of the journal.

With this January-February 2014 issue, we share two new milestones in our journal's life story. We begin with a new publisher, Springer International Publishing AG, one of the world's premier publishing houses - a move that will allow the influence of the journal to increase substantially. We are also

\section{R. Balon}

Wayne State University, Detroit, MI, USA

\section{E. V. Beresin}

Harvard Medical School, Boston, MA, USA

J. H. Coverdale

Baylor College of Medicine, Houston, TX, USA

M. Goldsmith • A. K. Louie $\cdot$ L. W. Roberts $(\triangle)$

Stanford University School of Medicine, Stanford, CA, USA

e-mail: RobertsL@stanford.edu

G. R. Tait

Dalhousie University, Halifax, Nova Scotia, Canada stretching to serve a broader community that includes teachers, learners, and leaders in psychiatry, the behavioral health sciences, and allied mental health professions internationally. This academic community is entrusted with building a better future for people living with and affected by mental illness throughout the world. With these milestones, our journal's purpose is strengthened. With these milestones, we expand its scope, extend its reach and impact, and enhance the way it works. (And while we remain the "Red Journal," we are sporting a new look too!) We editors express our gratitude to the Governance Board of the journal for its vision and support as we undertake these important next steps for Academic Psychiatry.

\section{Expanding Our Scope-Retrospection, Introspection: New Research and Colleagues}

During the early years, Academic Psychiatry's charge was unique in its focus: to improve medical education for psychiatric trainees and to support the educators engaged in that effort. The journal concentrated on scholarship presenting innovations in education, including the provision of sample didactic curricula and methods of training students and residents within clinical settings. The journal also highlighted commentaries, reviews, and personal reflection pieces. In 2002, the journal maintained this focus and gave attention to five critical performance domains:

(1) Fostering the value, standing, and contributions of the journal;

(2) Advancing the scholarship and methods of psychiatric education;

(3) Continuing to serve as a vehicle for academic development, extending the journals fundamental mentoring mission;

(4) Improving the mechanics of the publication process for the journal; and

(5) Strengthening the financial base of the journal. [1, 13] 
In keeping with these goals, the journal grew its sponsoring organizations from two (Association for Academic Psychiatry, American Association of Directors of Psychiatric Residency Training) to four (adding Association of Directors of Medical Student Education in Psychiatry, American Association of Chairs of Departments of Psychiatry) and advancing in technology to the use of electronic manuscript processing systems. The journal's impact factor sprouted from 0.4 in 2002 to $0.9-1.1$ recently [2], and its website received more than 400,000 visits in 2012 and an average of 350,000 visits during the past 5 years. All the while, the editors averaged 50 days to manage a paper from receipt to decision since 2003.

Now, in 2014, the journal will broaden its mission to encompass educational innovation, as in the past, but also give much more explicit attention to topics in leadership and administration; academic career and faculty development; professionalism and ethics; and the health and well-being of physicians, physicians-in-training, and medical and college students. To support our expanded scope, we are reaching out beyond our traditional borders, both conceptual and geographic.

We have progressively championed educational research characterized by clearly defined, rigorous methods; data-driven evidence; and the feasibility of replicating projects nationally and globally. Equally important as research in education is scholarship of discovery, integration, application, and teaching [3]. We want our journal to model dissemination of scholarship so that the many educators engaged in scholarship can elevate their work and receive credit for it by ensuring it holds up to the recognized assessment criteria [4]. Moreover, we have promoted, and will continue to promote, models of education and training that may be implemented in a broad range of academic and clinical systems. We have also encouraged increased attention to principles of adult learning (e.g., [5, 6]); a wider range of educational models and theory (e.g., $[6,7])$; and the use of modern technological advances in the educational mission (e.g., [8-10]). These efforts are consistent within the context of our profession, which requires life-long and practice-based learning and improvement. For these reasons, we place a larger emphasis on self-assessment and on understanding the common ground among the fields of continuing education, knowledge translation, quality improvement, and patient safety [11].

Coincidentally, 2014 is also the year of launching the Next Accreditation System (NAS) and Milestones in psychiatry in the USA. Academic Psychiatry will be among the first journals addressing the NAS in psychiatry, and we hope that our journal will be the platform for sharing the experiences with this new system and debating its merits, results, and consequences.

The Editorial Board is entrusted with reviewing manuscripts that have relevance to improving the knowledge, skills, and attitudes of our readers. On behalf of our readers, our goal is to support the professional development of all educational researchers and scholars, and for our authors, we aim to provide blinded peer reviews that are educational in themselves. In the past 10 years, on average, only $2 \%$ of new manuscript submissions were rejected without review. We also support the development of clinician educators in the domains of teaching, research, scholarship, and leadership across a continuum of experience. Many identify such interests early and are eager for learning opportunities and mentorship. In this vein, we want our audience to continue to include medical students and residents but embrace all who will be involved in the care of the mental health of patients and teach others to do the same.

The commitment of the journal to life-long learning and multi-disciplinary collaboration is also crucial for succession planning and for ensuring a strong legacy for education within the field of psychiatry and beyond. Our parent organizations offer trainee awards for writing, and we believe it is incumbent on us to guide award winners in their manuscript production and help them to consider research and scholarship in psychiatric education as part of their professional development. These are responsibilities we embrace with enthusiasm.

Whereas we continue to seek submissions rooted in quantitative methods, we recognize that rigorous qualitative research projects are also required to deepen our understanding of psychiatric education; the dynamic interaction among clinicians, patients, students, and teachers; and the complex system of care in which we are all embedded. Qualitative methods are particularly well suited to explore the hidden curriculum, specifically the transmission of culture and values and how one navigates and reconciles conflicting agendas and demands within practice and education. Similarly, in the spirit of capturing the human experience, our journal has a place for such important and varied topics as personal perspectives, case studies, and the use of poetry to enhance reflective practice.

In addition to increasing the type, number, and quality of our submissions, we are inviting submissions from authors in disciplines outside of psychiatry, including the behavioral health sciences and allied health professions that contribute to our mission. We welcome submissions from our allied health colleagues and from disciplines outside medicine that have important contributions to our mission, many of which reside in the social sciences and humanities - education, management/ leadership, ethics, college mental health, and sociology, to name a few. All of these academic realms offer conceptualizations that enhance our understanding of mental health and well-being.

Academic Psychiatry is committed to publishing the best educational research and scholarship from all around the world, and to supporting the career development of educators in all the domains encompassed therein-very much reflected in the overarching missions of our journal. In addition to seeking manuscripts from authors in other domains, we also seek more representation from our colleagues in other countries, places, and institutions around the globe. Although the fields of mental health and medical education have advanced significantly in terms of recognition in North America and Europe over the last decade, that is far from the case in many 
other parts of the world. In developing nations with limited resources and whose patients are marginalized and disadvantaged, we aim to connect clinicians, researchers, and educators in order to promote educational initiatives and support for those individuals working with these populations.

As much as we may have experience to share, we have much to learn from our colleagues from around the world [12]. We are invested in promoting the mental health of all individuals, those with and without diagnosed mental illness or easily accessible care, through collaboration with our colleagues across the globe. Our journal will therefore be delighted to do all that we can to facilitate the success of our international authors in developing ideas and contributions for publication. We recognize that authors from around the world will expect us to be receptive to their work and its specifics/uniqueness and to support their efforts to achieve standards for publication. We are looking forward with great enthusiasm and commitment to these opportunities.

\section{Extending our Reach and Influence}

As we expand our traditional boundaries, conceptually and geographically as outlined above, we are also revisiting the ways in which we support our stakeholders, authors, and readers alike. Our journal will provide mentoring for authors in developing ideas and contributions for publication. In this way, we can help potential contributors develop their skills and work so that their submissions achieve the high-quality standards required for publication. This mentoring may be particularly helpful for those potential contributors from countries or institutions that have not developed the research skills of health professionals as sufficiently as others. We will also support authors by maintaining a competitive turnaround time for submissions and providing online publication in advance of the print edition. We are also seeking to increase the diversity of our reviewers to support the diversity of publications. These last two developments are made possible by our partnership with Springer, our new publisher.

We are also expanding the ways in which we support our readers. We will be publishing a wider variety of submission types, including new columns featuring a day in the life of a student or educator and features such as black and white art. Overall, we will increase the number of articles, their methodological rigor, and diversity of methodological approaches, which will also contribute to our journal's impact, a boon for both readers and authors.

\section{Enhancing the Way We Work-Advancements in Publishing, Impact Factor, and Strengthening Ties}

Working with a new publisher will help us to achieve and enhance our mission and all our goals. With a larger, skilled, and experienced staff, our turnaround time of submissions to print will be quite short and reasonable. The articles will be published online once finally accepted, ahead of print. Whereas our editor and reviewer groups are diverse in experience and many other aspects, we are committed to recruiting and training new reviewers (those interested in becoming a reviewer should contact our editorial office) and also to broadening our editor group experience. This evolution from review to editing to publication would not be possible without our authors' contributions from all around the world! And to our past and future authors, we express our appreciation for your commitment to the profession and the individuals you serve.

We also recognize that authors, as the sustenance of the journal, will choose to publish in journals that are widely read, important, and respected in their field, and timely in their decision making and publication processes. Therefore, we also hope to grow our impact factor as it can also influence where authors choose to publish, and because it, in a way, reflects the relevance of the journal in its field. The authors and readers should beware that although the impact factor is usually used as a proxy for the role of the journal, it does not evaluate the quality and importance of individual work or the productivity and impact of the published work by an individual author/scholar. Those are more likely reflected in the citation impact or in the so-called H-index, or Hirsch index. Journal impact factor is a frequently used number but should be used with caution. It definitely should not be used to compare journals across the disciplines, for example, Academic Psychiatry should be compared to medical education journals and not to clinical or basic science journals. Thus, we would like to emphasize that while we are addressing the enhancement of Academic Psychiatryś impact factor, we are also seeking a balanced approach that promotes a rich, diverse, and exciting product by including articles on less well-known or appreciated topic areas [13], even though they might not enhance the impact factor, and by publishing a wide variety of article types.

As the editorial team of Academic Psychiatry, we express our appreciation to all those who are helping us to achieve our goals and mission - to our authors, readers, reviewers, sponsoring organizations, and editorial staff.

\section{References}

1. Roberts LW. Your journal, our journal. Acad Psychiatry. 2002;26(1): $1-3$.

2. Roberts LW, Coverdale JH, Balon R, et al. In celebration of the history of Academic Psychiatry. Acad Psychiatry. 2013;37(6):36974.

3. Boyer EL. Scholarship reconsidered: priorities of the professoriate. Princeton: Carnegie Foundation; 1990. 
4. Glassick CE. Boyer's expanded definitions of scholarship, the standards for assessing scholarship, and the elusiveness of the scholarship of teaching. Acad Med. 2000;75:877-80.

5. Goldman S. Enhancing adult learning in clinical supervision. Acad Psychiatry. 2011;35(5):302-6.

6. Feinstein RE, Yager J. Advanced psychotherapy training: psychotherapy scholars' track and the apprenticeship model. Acad Psychiatry. 2013;37:248-53.

7. Sunderji N, Malat J, Leszcz M. Group day: experiential learning about group psychotherapy for psychiatry residents at University of Toronto. Acad Psychiatry. 2013;37(5):352-4.

8. Cully J, Curry A, Ryan S, et al. Development of a computer-aided training program for brief cognitive-behavioral therapy in primary care. Acad Psychiatry. 2013;37(2):120-4.
9. Keyneyad R, Ali FR, Finlayson AE, et al. Telemedicine for peer-topeer psychiatry learning between UK and Somaliland medical students. Acad Psychiatry. 2013;37:182-6.

10. Zisook S, Benjamin S, Balon R, et al. Alternate methods of teaching psychopharmacology. Acad Psychiatry. 2005;29:141-54.

11. Kitto SC, Bell M, Goldman J, et al. (Mis)perceptions of continuing education: insights from knowledge translation, quality improvement, and patient safety leaders. J Contin Educ Health Prof. 2013;33(2):81-8.

12. Balon R, Roberts LW, Coverdale J, et al. Globalization of medical and psychiatric education and the focus of Academic Psychiatry on the success of "international" authors. Acad Psychiatry. 2008;32(2):151-3.

13. Coverdale JH, Roberts LW, Balon R, et al. Improving the "impact" of Academic Psychiatry. Acad Psychiatry. 2008;32(3):169-72. 